\title{
Prevalence and Risk Factors of Asthma among People aged 45 and Older in Mainland China: A Cross-sectional Study from CHARLS in 2018
}

Jingxuan Wan

China-Japan Friendship Hospital

Qing Zhang

China-Japan Friendship Hospital

Chunxiao Li

China-Japan Friendship Hospital

Jiangtao Lin ( $\square$ jiangtao_l@263.net )

China-Japan Friendship Hospital

\section{Research Article}

Keywords: Asthma, Prevalence, Trends, Epidemiology, Risk factors, China

Posted Date: January 5th, 2021

DOl: https://doi.org/10.21203/rs.3.rs-136671/v1

License: (a) (i) This work is licensed under a Creative Commons Attribution 4.0 International License. Read Full License 
1 Prevalence and risk factors of asthma among people

2 aged 45 and older in mainland China: a cross-sectional

3 study from CHARLS in 2018

4 Jingxuan Wan ${ }^{1,2}$, Qing Zhang ${ }^{1,2}$, Chunxiao Li ${ }^{1,3}$, Jiangtao Lin ${ }^{1 *}$

$5 *$ Corresponding author:

6 E-mail: jiangtao_1@263.net(J. Lin).

$7 \quad{ }^{1}$ Department of Pulmonary and Critical Care Medicine, Center of Respiratory

8 Medicine, China-Japan Friendship Hospital, Beijing, China.

9 Full list of author information is available at the end of the article

10

11

12

13

14

15

16

17

18

19

20

21 


\section{Abstract}

Background: Asthma is one of the most prevalent chronic respiratory disease worldwide. The survey aims to describe the updated prevalence and risk factors of asthma among individuals aged 45 and older in mainland China.

Methods: The data for this study come from the fourth wave of China Health and Retirement Longitudinal Study (CHARLS) conducted by the National School of Development of Peking University in 2018. CHARLS is a nationally representative survey targeting populations aged 45 and over from 28 provinces/cities in mainland China. A representative sample of 19816 participants were recruited for the study using a multi-stage stratified sampling method. The prevalence of asthma was described across different characteristics. The potentially risk factors were examined by multivariable logistic regressions.

Results: A total of 18504 participants (8759 men and 9745 women) were eligible for the final data analysis. The estimated prevalence of asthma among Chinese people age $\geq$ 45 years in 2018 was $2.16 \%$ (95\%CI $1.96-2.38)$. The prevalence of asthma significantly differs according to race $(P=0.002)$, with an overall rate of $2.06 \%(95 \%$ CI $1.86-2.29)$ in Han and 3.28\% (95\%CI 2.47-4.34) in minorities. Furthermore, the minorities $(\mathrm{OR}=1.54$ [95\% CI 1.114-2.122], $P=0.009)$, elderly people (60-69 years group: $\mathrm{OR}=$ 2.65 [95\% CI $1.230-5.702], P=0.013 ; \geq 70$ years group: OR=3.38 [95\% CI 1.741 8.036], $P=0.001$ ), middle-school education and below (middle-school education: $\mathrm{OR}=1.91[95 \% \mathrm{CI}: 0.678-1.193], P=0.009$; primary education: $\mathrm{OR}=2.59$ [95\% CI 0.675 - 
43

1.199], $P<0.001$; literate: $\mathrm{OR}=2.60$ [95\% Cl 0.480- 0.928; illiterate: $\mathrm{OR}=2.89$ [95\% CI 0.220-0.572]), smoking $(\mathrm{OR}=1.36 \quad[95 \%$ CI 1.109-1.677], $P=0.003)$, North $(\mathrm{OR}=1.51[95 \%$ CI 1.02-2.078], $P=0.01)$ or Northwest China residence $(\mathrm{OR}=1.70[95 \%$ CI 1.170-2.472], $P=0.005$ ) were associated with prevalent asthma.

Conclusions: Asthma is prevalent but underappreciated among middle-aged and elderly people in China. A number of risk factors were identified. These results can help to formulate correct prevention and treatment measures for asthma.

Key words: Asthma, Prevalence, Trends, Epidemiology, Risk factors, China

2

3

4

5

6

(2)

58

9

0

1




\section{Background}

Asthma is one of the most prevalent chronic respiratory disorder, which is a major cause of disability, health resource utilization and socioeconomic burden worldwide ${ }^{1-}$

3. The World Health Survey (WHS) reported the global prevalence rates of doctor diagnosed asthma among individuals aged 18 to 45 years were $4.3 \%$ in $2002-2003^{4}$.

Global Initiative for Asthma (GINA) Dissemination Committee Report estimated that asthma affects 300 million people worldwide in $2004^{5}$. The population with asthma worldwide increased to 358 million identified by Global Burden of Disease (GBD) Study in 2015 and the number is predicted to rise to 400 million by $2025^{5}$. Obviously, with the rapid development of global industrialization and urbanization, changes in the ecological environment, the prevalence of asthma were showing an upward trend.

In China, the China Asthma and Risk factors Epidemiologic(CARE) study reported provinces/cities in $2012^{6}$. China Pulmonary Health (CHP) study reported this prevalence to be $4.2 \%$ in adults aged $\geq 20$ years, on the basis of wheeze symptoms in the preceding 12 months or previous diagnosis by a physician from ten provinces/cities in $2015^{7}$. Differences in diagnosis of asthma and data collection might contribute to this

81 inconsistency. All along, much attention has focused on childhood and adult asthma ${ }^{8,9}$,

82 but the population is ageing rapidly in China ${ }^{10,11}$ and many studies demonstrated the 83 prevalence of asthma increased with age ${ }^{7}$. Therefore, it is desperately indispensable to 84 describe the prevalence of asthma in middle-aged and elderly people. However, these 
current studies are not up-to-date and cannot reflect the recent prevalence of asthma among middle-aged and elderly people in China.

Here, we used data from the CHARLS survey to describe the latest prevalence of asthma in Chinese individuals aged 45 years and older in 2018 and to assess the risk factors for asthma.

\section{Methods}

\subsection{Study design and population}

The current analysis base on the data from the fourth wave of CHARLS survey conducted by the National School of Development of Peking University in 2018. The details of the sampling design of this survey has been described previously ${ }^{12}$. Briefly, CHARLS is a nationally representative survey targeting populations aged 45 and older from 450 villages/urban communities in 150 counties/districts in 28 provinces/cities in mainland China that provides information about demographics, geography, health status, and lifestyle variables. The study was carried out in 2018 with a response rate of $86 \%$. The geographic and population distribution of 28 provinces/cities was presented in Fig. 1.

Overall, a total of 19816 participants were recruited for CHARLS in 2018, of whom 1312 were excluded due to incomplete information or age $<45$ years. Eventually, 18045 participants were enrolled (see Fig. 2). Meanwhile, the Medical Ethics Committee approved the CHARLS study, and all interviewees were required to sign an informed consent form. Ethics approval for the data collection in CHARLS was obtained from 
the Biomedical Ethics Review Committee of Peking University (IRB00001052-11015).

107 Ethics approval for the use of CHARLS data was obtained from the University of

108 Newcastle Human Research Ethics Committee (H-2015-0290).

110 At each county or district unit, trained staff collected data according to a standard

111 protocol in respondents' homes and local health stations or the local office of the China

112 Center for Disease Prevention and Control (CDC). For each participant, an interview

113 was conducted to collect information on sociodemographic characteristics (race, age,

114 sex and education), geographic residence, lifestyle features (smoking, type of cooking

115 fuels).

116 According to self-reported physician diagnosis of asthma, subjects were classified

117 into two groups: Asthma and Non-Asthma. The participants' race was classified as Han

118 and Minorities (Zhuang, Man, Hui, Miao, Weiwuer, Tujia,Yi, Mongol, Zangand or

119 other). The participants were divided into four groups according to their age, namely

120 45-49 years old group, 50-59 years, 60-69 years, $\geq 70$ years. The Educational

121 attainments were classified as illiterate (no formal education), literate (did not finish

122 primary school but capable of reading or writing), primary education (graduated from

123 elementary school), and middle-school education (graduated from middle school) and

124 high-school education above (graduated from high school, vocational school, college

125 or post-graduate school). The participants' residence was classified as urban, urban-

126 rural area or rural and categorized into six geographic regions, namely East China, 
China $^{13}$. According to the participants' smoking status, they were classified as neversmokers and smokers (smokers were defined as smoking more than 100 cigarettes in

130 your life). The types of cooking fuels were classified as clean (natural gas, marsh gas,

131 liquefied petroleum gas or electricity), unclean (coal, crop residue or wood burning).

$132 \quad 2.3$. Quality control

133 Fieldwork was conducted by independent enumerators who collected data using 134 face-to-face computer assisted personal interview. Data were verified by CHARLS 135 headquarters. Futhermore, the first two interviews were recorded to verify that 136 participants performed the correct procedures. If the recording could not be completed 137 owing to technical or other problems, CHARLS headquarters would call backfor a 138 phone check. Above technicians were trained to avoid information bias. Additionally, 139 multistage stratified cluster sampling was used to resolve selection bias. Confounding 140 factors was addressed with multivariable-adjusted logistic regression analysis.

141 2.4. Statistical analysis

142 In this study, the estimation of prevalence, risk factors of asthma were weighted by 143 considering the study design and individual weight with individual and household non144 response adjustment ${ }^{14}$. Metrical data with normal distribution were presented as 145 mean \pm standard deviation. Categorical data were presented as absolute counts and 146 percentages. We assessed the differences of the proportions by Chi-square test. The 147 associations between asthma and different characteristic variables were firstly explored 
148 by univariate logistic regressions. Then we identified the potential risk factors by

149 multivariable logistic regressions. Data clean and analysis were performed using Stata

150 statistical software (version 15.0; Stata Corporation, College Station, TX, USA). P-

151 value $<0.05$ was regarded as statistically significant.

\section{3. Results}

153 3.1. Demographic

154 The study included 18504 subjects ( 8759 men and 9745 women) who aged 45 years

155 and older and completed the survey. Of the total subjects, 17072 (92.26\%) were Han

156 Chinese and 1432 (7.74\%) were other origins. Furthermore, 7761(41.94\%) subjects

157 were smokers. The distribution of our study population by general characteristics is

158 summarized in Table 1.

159 3.2. Prevalence of asthma in 2018

160 Of the 18504 subjects, 399 were diagnosed with asthma. The total prevalence of

161 asthma in Chinese people aged 45 years and older was estimated $2.16 \%$ (95\% CI 1.96162 2.38).

163 3.3. The prevalence of asthma with different characteristics

164 Among people aged 45 and over in China, the prevalence of asthma with Han and

165 other ethnic groups was $2.06 \%$ (95\% CI $1.86-2.29)$ and $3.28 \%$ (95\% CI $2.47-4.34)$,

166 respectively $(P=0.002)$. The prevalence of asthma significantly increased with age,

167 from $0.77 \%(95 \%$ CI $0.37-1.60)$ in individuals aged 45 to 59 years to $3.29 \%(95 \%$ CI

168 2.84-3.82, $P<0.001)$ in those aged 70 years and older. The prevalence of asthma 

2.41-3.45) in adults who were illiterate to $0.91 \%(95 \%$ CI $0.61-1.38 P<0.001)$ in those

171 who educated from high-school or above. We found that it significantly varied between

172 different geographic regions in China, ranging from $1.56 \%(95 \%$ CI $1.01-2.41)$ in

173 eastern China to 3.14 (95\% CI $2.32-4.24)$ in Northwest China $(P=0.005)$. In never-

174 smokers, the prevalence of asthma was $1.90 \%$ (95\% CI 1.66-2.17), compared with $2.51 \%$

$175(95 \%$ CI $2.19-2.89)$ in smokers $(P=0.005)$. The prevalence of asthma was $1.95 \%(95 \%$

176 CI 1.73-2.20) for those who use clean cooking fuels and 2.64\% (95\% CI 2.25-3.10,

$177 \mathrm{P}=0.03$ ) for those who use unclean cooking fuels. However, asthma prevalence did not

178 differ between men (2.29\% [95\% CI 1.86-2.29]) and women (2.03\% [95\% CI $1.77-$

$1792.33], P=0.219)$ or between urban (1.86\% [95\% CI 1.48-2.35]), urban-rural (1.85\% [95\%

180 CI 1.28-2.67]) and rural (2.27\% [95\% CI 2.03-2.54], $\mathrm{P}=0.217)$ area. The prevalence of

181 asthma stratified according to different characteristics was presented in Table 2.

182 3.4 Socio-demographic, geographic and lifestyle factors associated with asthma

183 These statistically significant variables in the univariate model including race, age,

184 education, geographic region, smoking status, cooking fuels were analyzed in the

185 multivariable analysis. Multivariable logistic regressions analysis was performed for

186 control for the effect of potentially confounding variables. Finally, it showed that the

187 risk factors for asthma include the minorities, elderly people, smokers and North or

188 Northwest China residence, while people with middle-school education and above are

189 the protective factor for asthma. Minorities demonstrated to be a risk factor for asthma 
190

191

192

193

194

195

196

197

198

199

200

201

202

203

204

205

206

207

208

209

compared with Han (OR=1.54 [95\% CI 1.114-2.122], $P=0.009)$. Those who aged 60 years or older had a higher risk to suffer from asthma than those who aged 45 years to 49 years(60-69 years group: $\mathrm{OR}=2.65$ [95\% CI 1.230-5.702], $P=0.013 ; \geq 70$ years group: $\mathrm{OR}=3.38[95 \% \mathrm{CI} 1.741-8.036], P=0.001)$. The prevalence of asthma was higher among smokers than non-smokers ( $\mathrm{OR}=1.36$ [95\% CI 1.109-1.677], $P=0.003)$. People living in North or Northwest China had a higher risk than those who living in East China (North China: OR=1.51[95\% CI 1.02-2.078], $P=0.01$; Northwest China: $\mathrm{OR}=1.70$ [95\% CI 1.170-2.472], $P=0.005$ ). Additionally, subjects with middle-school education and below had a higher risk than those who were graduated from high-school or above (middle-school education: $\mathrm{OR}=1.91$ [95\%CI: $0.678-1.193], P=0.009$; primary education: $\mathrm{OR}=2.59$ [95\% CI 0.675-1.199], $P<0.001$; literate: $\mathrm{OR}=2.60$ [95\% $\mathrm{Cl} 0.480$ 0.928; illiterate: $\mathrm{OR}=2.89$ [95\% CI 0.220-0.572] ). There were no definite differences in asthma rates according to fuels type of cooking. The multivariable results were presented in Table 3.

\section{Discussion}

Our large comprehensive asthma survey in a nationally representative sample of Chinese individuals aged $\geq 45$ years indicated that the total estimated prevalence of asthma in China in 2018 was $2.16 \%$. The prevalence of asthma was higher among minorities than Han (3.28\% vs $2.06 \%$ ). In addition, we observed that the prevalence of asthma was the highest in people aged $\geq 70$ years $(3.29 \%)$, illiterate $(2.88 \%)$ and 
210 Northwest China (3.14\%). Smokers were linked to a higher risk of asthma than non-

211 smokers $(2.51 \%$ vs $0.19 \%)$.

212 A cross-sectional survey based on CHRLS in 2011 published that the prevalence of

213 asthma among individuals aged $\geq 45$ years in China was $1.33 \%{ }^{15}$. However, some of

214 these asthma patients were classified as Asthma-Chronic obstructive pulmonary disease

215 overlap (ACO) groups, which leaded to a lower prevalence of asthma than the value of

$2162.16 \%$ reported by our study. The CARE study was performed in 2010-2012, including

217164215 Chinese people aged $>14$ years from eight provinces/cities (Shanghai,

218 Guangdong, Beijing, Jiangsu, Sichuan, Henan, Liaoning and Shanxi), which estimated

219 that the prevalence of asthma among individuals aged $>14$ years in mainland China was

$2201.24 \%$. Our study was a large-scale investigation geographically covered 28 out of 31

221 provinces in mainland China. It reported that the rate of asthma among people aged $\geq$

22245 years was $2.16 \%$, which was similar to the value of $2.18 \%$ among people aged $>50$

223 years reported by CARE study ${ }^{6}$. Furthermore, the CHP study reported this prevalence

224 to be $4.2 \%$ based on wheeze symptoms or physician diagnosis from ten provinces/cities

225 in 2015, which was higher than our study. Although the demographic characteristics of

226 the subjects in these studies were not exactly matched, the higher prevalence reported

227 by CHP study may be partly explained by diagnostic criterion including wheeze

228 symptoms, which could potentially have led to the misclassification of Chronic

229 Obstructive Pulmonary Disease(COPD) as asthma due to both diseases present with

230 wheezing 7 . Additionally, in the middle-aged and elderly population, the older the age, 
231 the higher the prevalence of asthma $a^{6,7,15}$. Given that China has the largest aging 232 population in the world, and is one of the highest aging rates in the world today ${ }^{10}$, it is 233 essential to pay more attention to the asthma among people aged $\geq 45$ years.

234 Multivariate analysis demonstrated that the primary risk factors of asthma among 235 people aged $\geq 45$ years were minorities, elderly people ( $\geq 60$ years), middle-school 236 education and below, smokers, North and Northwest China residence. Data generated 237 from countries with multi-ethnic populations presented significant differences in the 238 relative rates of asthma by ethnicity. In the United States, for example, the prevalence 239 of asthma among Hispanics, Caucasians, African Americans, and Puerto Ricans was $2406.6 \%, 7.8 \%, 10.3 \%$, and $13.7 \%$, respectively ${ }^{16-19}$. UK data suggested the prevalence of 241 asthma was higher in those of African descent and lower in South Asians as compared 242 with Caucasians ${ }^{20,21}$. In contrast, the Han Chinese were significantly associated with 243 decreased prevalence of asthma, independent of other risk factors. Genetics clearly 244 plays a role in the link between asthma and ethnicity. But, thus far, no specific gene has 245 been exactly explained an ethnic susceptibility to asthma. Theo J. Moraes et al. 246 proposed that asthma is a heterogeneous disease caused by complex interactions 247 between genetic and environmental factors ${ }^{22}$. Further research into the race-related 248 causes of asthma is needed. Ethnic variation in asthma prevalence helps to formulate 249 correct prevention and treatment measures for asthma.

250 Recent studies suggested a relationship between asthma and age. Those studies 251 indicated that the prevalence of asthma increased with age ${ }^{6,23-25}$, consistent with our 
study. For people aged 45-49 years, the odds of asthma among people aged 60-69 years

253 were approximately increased by 2.6 folds and those over 70 were increased by 3.7

254 folds. In Korea, a survey of adult asthma incidence based on National Health Insurance

255 Service-National Sample Cohort (NHIS-NSC) observed that incidence rates increased

256 with age, subjects aged 70 or over showed the highest asthma prevalence ${ }^{26}$.

257 Furthermore, some studies have reported that the aggravation rate and mortality rate of

258 asthma patients over 55 years old were significantly increased ${ }^{25}$, suggesting the

259 necessary to pay more attention to the aged and strengthen the care of asthmatics who

260 over 60 years old.

261 Recent studies observed a relationship between asthma and smoking. In a case-

262 control study, the population consisted of adults aged 21-63 years, reported that the

263 risk of asthma was higher among smokers with a odds ratio of 1.33 than never-

264 smokers $^{27}$,which was similar to the odds ratio of 1.36 in our study. On the other hand,

265 Cigarette smoking and asthma interact to trigger certain adverse effects on clinical,

266 therapeutic and prognostic outcomes ${ }^{28}$. Quitting smoking can improve lung function

267 and symptoms, but the low rates of smoking cessation emphasise the need for improved

268 strategies for managing these patients.

269 Besides above, the prevalence of asthma significantly differs according to different

270 regions in mainland China. The prevalence of asthma in East China, North China,

271 Northeast China, South Central China, Southwest China was 1.86\%, 2.67\%, 1.56\%,

$2723.14 \%, 1.88 \%$ and $2.48 \%$, respectively. The prevalence of asthma in Northern and 
273 Northwestern China was 1.5 to 1.7 times higher than in Eastern China and the two 274 regions should be drawn more attention. Another notable risk factor was middle-school 275 education and below, which was significantly correlated with the risk of asthma in 276 accordance with previous studies ${ }^{7,15}$. With the lower education attainment, the 277 prevalence of asthma increased. Compared with those who graduated from high-school 278 and above, the risk of asthma was 1.91 times for those who graduated from middle279 school, 2.59 times for those who graduated from elementary school, 2.60 times for 280 those who were literate and 2.89 times for those who were illiterate. It can be interpreted 281 as the lower the level of education, the less the health consciousness and the worese the 282 living environment.

283 Conflicting results have been reported regarding the association of gender with asthma 284 prevalence ${ }^{7,29}$. A survey from three cross-sectional samples in Sweden showed that the 285 increase in asthma was most pronounced among women from 1996 to $2016^{29}$. But, the 286 CHP study showed the asthma prevalence did not differ between male and female, 287 consistent with our study. The reason may be caused by the higher smoking of male in 288 China. We also observed that those who lived in rural not did provide protection from 289 asthma in accordance with other studies ${ }^{30,31}$. In fact, the difference in asthma caused 290 by urban and rural was still connected with the environment. There was sufficient 291 evidence to suggest that air pollutants, such as ozone and particulate matter, trigger 292 exacerbations of asthma, decrease lung function and increase rates of asthma ${ }^{32}$. The 
result may be masked by the stronger effort of smoking ${ }^{7}$ or indicate that a rapid decrease

294 in air pollution is already occurring in China.

295 The univariate results in this survey demonstrated that the prevalence of asthma was 296 higher in individuals with unclean cooking fuels than in those with clean cooking fuel. 297 But multivariate regression analysis suggested that the type of cooking was not really 298 relevant to asthma, consistent with the CHP study ${ }^{6}$. Actually, it also observed that the 299 asthma risk of biomass use might be masked by the stronger effect of smoking ${ }^{7}$, which 300 needs further research to confirm.

301 This study has the following advantages. First, CHARLS is a nationally 302 representative survey targeting populations aged 45 and older from 450 villages or 303 communities in 150 counties or districts in 28 provinces of mainland China, which 304 enabled us to estimate the prevalence of asthma. Second, this study adopted a 305 multistage cluster sampling in six areas of mainland China (East China, North China, 306 Northeast China, Northwest China, South Central China and Southwest China), which 307 avoided selection bias. Third, strict quality control assured a high quality of data 308 collection and reliability of the findings. This study also has several limitations. On the 309 one hand, we did not include individuals younger than 45 years. Thus we cannot 310 provide information on those who aged $<45$ years. One the other hand, asthma was 311 identified by self-reported physician diagnoses rather than spirometry measurements, 312 but it also reflexed the prevalence of asthma in mainland China.

\section{Conclusions}


315 China. The risk factors for asthma include the Minorities, elderly people, illiterate and

316 North or Northwest China residence. These results can help to formulate correct 317 prevention and treatment measures for asthma.

\section{Declarations}

\section{Abbreviations}

320 CHARLS: China Health and Retirement Longitudinal Study; WHS: World Health 321 Survey; GINA: Global Initiative for Asthma; GBD: Global Burden of Disease; CARE: 322 China Asthma and Risk factors Epidemiologic; CHP: China Pulmonary Health; CDC: 323 China Center for Disease Prevention and Control; NHIS-NSC: National Health 324 Insurance Service-National Sample Cohort.

\section{Acknowledgements}

326 We thank the China Health and Retirement Longitudinal Study (CHARLS) team for 327 providing data.

\section{Funding}

329 No funding

\section{$330 \quad$ Availability of data and materials}

331 The datasets used and/or analysed during the current study are available from the

332 corresponding author on reasonable request.

\section{Ethics approval and consent to participate}

334 The study was conducted in accordance with the declaration of Helsinki. 
335 The study was approved by the Biomedical Ethics Review Committee of Peking 336 University (IRB00001052-11015). Ethics approval for the use of CHARLS data was 337 obtained from the University of Newcastle Human Research Ethics Committee (H338 2015-0290). And all the participants gave their written informed consent before any 339 study procedures began.

340 Competing interests

341 The authors declare that they have no competing interests.

\section{Consent for publication}

343 Not applicable.

\section{Authors' contributions}

345 Study design: JW, JL; Data analysis: JW, QZ, CL; Paper writing: JW; Paper revise: JL. 346 All authors read and approved the final manuscript.

\section{$347 \quad$ Author details}

$348{ }^{1}$ Department of Pulmonary and Critical Care Medicine, China-Japan Friendship 349 Hospital, Beijing, China. ${ }^{2}$ Chinese Academy of Medical Sciences/Peking Union 350 Medical College, Beijing, China. ${ }^{3}$ Peking University Health Science Center, Beijing, 351 China. 
356

357

358

359

360

361

362

363

364

365

366

367

368

369

370

371

372

373

374

375

376 


\section{REFERENCES}

378 1. Soriano JB, Abajobir AA, Abate KH, et al. Global, regional, and national deaths, 379 prevalence, disability-adjusted life years, and years lived with disability for chronic 380 obstructive pulmonary disease and asthma, 1990-2015: a systematic analysis for the 381 Global Burden of Disease Study 2015. The Lancet Respiratory Medicine 2017; 5(9): $382 \quad 691-706$.

383 2. Sullivan PW, Ghushchyan VH, Slejko JF, Belozeroff V, Globe DR, Lin SL. The 384 burden of adult asthma in the United States: evidence from the Medical Expenditure 385 Panel Survey. J Allergy Clin Immunol 2011; 127(2): 363-9 e1-3.

386 3. Nurmagambetov T, Kuwahara R, Garbe P. The Economic Burden of Asthma in the 387 United States, 2008-2013. Ann Am Thorac Soc 2018; 15(3): 348-56.

388 4. To T, Stanojevic S, Moores G, et al. Global asthma prevalence in adults: findings 389 from the cross-sectional world health survey. BMC Public Health 2012; 12: 204.

390 5. Masoli M, Fabian D, Holt S, Beasley R, Global Initiative for Asthma P. The global 391 burden of asthma: executive summary of the GINA Dissemination Committee report. 392 Allergy 2004; 59(5): 469-78.

393 6. Lin J, Wang W, Chen P, et al. Prevalence and risk factors of asthma in mainland 394 China: The CARE study. Respir Med 2018; 137: 48-54.

395 7. Huang K, Yang T, Xu J, et al. Prevalence, risk factors, and management of asthma 396 in China: a national cross-sectional study. The Lancet 2019; 394(10196): 407-18. 
8. Y.Z. Chen NCGoCA. A nationwide survey in China on prevalence of asthma in urban children. Zhonghua Er Ke Za Zh 2003; 41 123-127.

9. National Cooperative Group on Childhood A IoEH, Related Product Safety CCfDC, et al. Third nationwide survey of childhood asthma in urban areas of China. Zhonghua Er Ke Za Zhi 2013; 51 729-735.

Gewei Wang, Huali Wang. China Health and Retirement Longitudinal Study Wave 4

User's Guide. National School of Development, Peking University 2020. of China. Beijing: China Statistics Press 2012.

411 Retirement Longitudinal Study (CHARLS). Int J Epidemiol 2014; 43(1): 61-8.

412 15. Song $\mathrm{P}$, Zha M, Xia W, Zeng C, Zhu Y. Asthma-chronic obstructive pulmonary 413 disease overlap in China: prevalence, associated factors and comorbidities in middle414 aged and older adults. Curr Med Res Opin 2020; 36(4): 667-75.

415 16. Bhan N, Kawachi I, Glymour MM, Subramanian SV. Time Trends in Racial and 416 Ethnic Disparities in Asthma Prevalence in the United States From the Behavioral Risk 
417 Factor Surveillance System (BRFSS) Study (1999-2011). Am J Public Health 2015; 418 105(6): 1269-75.

419 17. Davis AM, Kreutzer R, Lipsett M, King G, Shaikh N. Asthma prevalence in 420 Hispanic and Asian American ethnic subgroups: results from the California Healthy 421 Kids Survey. Pediatrics 2006; 118(2): e363-70.

422 18. Gorman BK, Chu M. Racial and ethnic differences in adult asthma prevalence, 423 problems, and medical care. Ethn Health 2009; 14(5): 527-52.

424 19. Lara M, Akinbami L, Flores G, Morgenstern H. Heterogeneity of childhood asthma 425 among Hispanic children: Puerto Rican children bear a disproportionate burden. 426 Pediatrics 2006; 117(1): 43-53.

427 20. Kuehni CE, Strippoli MP, Low N, Silverman M. Asthma in young south Asian 428 women living in the United Kingdom: the importance of early life. Clin Exp Allergy $429 \quad 2007 ; 37(1): 47-53$.

430 21. Netuveli G, Hurwitz B, Sheikh A. Ethnic variations in incidence of asthma 431 episodes in England \& Wales: national study of 502,482 patients in primary care. 432 Respir Res 2005; 6: 120.

433 22. Moraes TJ, Sears MR, Subbarao P. Epidemiology of Asthma and Influence of 434 Ethnicity. Semin Respir Crit Care Med 2018; 39(1): 3-11.

435 23. Wu F, Guo Y, Kowal P, et al. Prevalence of major chronic conditions among older 436 Chinese adults: the Study on Global AGEing and adult health (SAGE) wave 1. PLoS 437 One 2013; 8(9): e74176. 
24. Kim YK, Kim SH, Tak YJ, et al. High prevalence of current asthma and active smoking effect among the elderly. Clin Exp Allergy 2002; 32(12): 1706-12.

25. Bloom CI, Nissen F, Douglas IJ, Smeeth L, Cullinan P, Quint JK. Exacerbation risk and characterisation of the UK's asthma population from infants to old age. Thorax 2018; 73(4): 313-20.

26. Shin JY, Sohn KH, Shin JE, et al. Changing patterns of adult asthma incidence: results from the National Health Insurance Service-National Sample Cohort (NHISNSC) database in Korea. Sci Rep 2018; 8(1): 15052.

27. Piipari R, Jaakkola JJ, Jaakkola N, Jaakkola MS. Smoking and asthma in adults. Eur Respir J 2004; 24(5): 734-9.

28. Polosa R, Thomson NC. Smoking and asthma: dangerous liaisons. Eur Respir J 2013; 41(3): 716-26.

29. Backman H, Raisanen P, Hedman L, et al. Increased prevalence of allergic asthma from 1996 to 2006 and further to 2016-results from three population surveys. Clin Exp Allergy 2017; 47(11): 1426-35.

30. Sanchez J, Sanchez A, Cardona R. Clinical differences between children with asthma and rhinitis in rural and urban areas. Colomb Med (Cali) 2018; 49(2): 169-74.

31. Keet CA, Matsui EC, McCormack MC, Peng RD. Urban residence, neighborhood poverty, race/ethnicity, and asthma morbidity among children on Medicaid. $J$ Allergy Clin Immunol 2017; 140(3): 822-7. 
458 32. Tatum AJ, Shapiro GG. The effects of outdoor air pollution and tobacco smoke on

459 asthma. Immunol Allergy Clin North Am 2005; 25(1): 15-30.

460

461

462

463

464

465

466

467

468

469

470

471

472

473

474

475

476

477

478 
479 Table 1 General characteristics of the participants among aged 45 and older

\begin{tabular}{lccc}
\hline Characteristic & Non- Asthma & Asthma & Overall \\
\hline Participants & $18105(97.8 \%)$ & $399(2.16 \%)$ & $18504(100 \%)$ \\
Race & & & \\
Han & $16720(92.4 \%)$ & $352(88.2 \%)$ & $17072(92.3 \%)$ \\
Minorities & $1385(7.6 \%)$ & $47(11.8 \%)$ & $1432(7.7 \%)$
\end{tabular}

Sex

Male

$8558(47.3 \%) \quad 201(50.4 \%)$

$8759(47.3 \%)$

Female

$9547(52.7 \%) \quad 198(49.6 \%)$

9745 (52.7\%)

\section{Age group}

$\begin{array}{lccc}45-49 \text { years } & 908(5.0 \%) & 7(1.8 \%) & 915(4.9 \%) \\ 50-59 \text { years } & 6384(35.3 \%) & 92(23.0 \%) & 6476(35.0 \%) \\ 60-69 \text { years } & 5880(32.5 \%) & 132(33.1 \%) & 6012(32.5 \%) \\ \geq 70 \text { years } & 4933(27.2 \%) & 168(42.1 \%) & 5101(27.6 \%)\end{array}$

\section{Education}

$\begin{array}{llll}\text { High-school or above } & 2390(13.2 \%) & 22(5.5 \%) & 2412(13.0 \%) \\ \text { Middle-school } & 4042(22.3 \%) & 67(16.8 \%) & 4109(22.2 \%) \\ \text { Primary education } & 3985(22.0 \%) & 98(2.5 \%) & 4083(22.1 \%) \\ \text { Literate } & 3748(20.7 \%) & 95(23.8 \%) & 3843(20.8 \%) \\ \text { Illiterate } & 3940(21.8 \%) & 117(29.3 \%) & 4057(21.9 \%)\end{array}$

\section{Residence setting}


Urban

Urban-rural area

Rural

Geographic region

East

North

Northeast

Northwest

South Central

Southwest

\section{Smoking status}

Never-smokers

Smokers

\section{Type of cooking}

Clean

$12725(70.3 \%)$

$253(63.4 \%)$

$12978(70.1 \%)$

Unclean
$3684(20.3 \%)$

$1485(8.2 \%)$

$12936(71.5 \%)$

$5584(30.8 \%)$

$2517(13.9 \%)$

$1260(7.0 \%)$

$1265(7.0 \%)$

$3145(23.9 \%)$

$3145(17.4 \%)$

$80(20.0 \%)$

$3225(17.4 \%)$
$1513(8.2 \%)$

$13237(71.5 \%)$ 
485 Table 2 The prevalence of asthma by different characteristics among people aged 45 486 and older

\begin{tabular}{|c|c|c|}
\hline Characteristic & Prevalence $(\%)$ & $95 \% \mathrm{CI}$ \\
\hline \multicolumn{3}{|l|}{ Race } \\
\hline Han & $2.06 \%$ & $1.86-2.29$ \\
\hline Minorities & $3.28 \%$ & $2.47-4.34$ \\
\hline \multicolumn{3}{|l|}{ Sex } \\
\hline Male & $2.29 \%$ & $2.00-2.63$ \\
\hline Female & $2.03 \%$ & $1.77-2.33$ \\
\hline \multicolumn{3}{|l|}{ Age group } \\
\hline $45-49$ years & $0.77 \%$ & $0.37-1.60$ \\
\hline $50-59$ years & $1.42 \%$ & $1.16-1.74$ \\
\hline 60-69 years & $2.20 \%$ & $1.85-2.60$ \\
\hline$\geq 70$ years & $3.29 \%$ & $2.84-3.82$ \\
\hline
\end{tabular}

Education $<0.001$

$\begin{array}{lcc}\text { High-school or above } & 0.91 \% & 0.60-1.38 \\ \text { Middle-school } & 1.63 \% & 1.29-2.07 \\ \text { Primary education } & 2.40 \% & 1.97-2.92 \\ \text { Literate } & 2.47 \% & 2.03-3.01 \\ & & \\ \text { Illiterate } & 2.88 \% & 2.41-3.45\end{array}$

Residence setting 

Urban
$1.86 \%$
$1.48-2.35$
Urban-rural area
$1.85 \%$
$1.28-2.67$
Rural
$2.27 \%$
2.03-2.54

Geographic region

0.005

$\begin{array}{lcc}\text { East } & 1.86 \% & 1.51-2.28 \\ \text { North } & 2.67 \% & 2.11-3.36 \\ \text { Northeast } & 1.56 \% & 1.01-2.41 \\ \text { Northwest } & 3.14 \% & 2.32-4.24 \\ \text { South Central } & 1.88 \% & 1.55-2.28 \\ & & \\ \text { Southwest } & 2.48 \% & 2.00-3.08\end{array}$

Smoking status

0.005

Never-smokers

$1.90 \%$

1.66- 2.17

Smokers

$2.51 \%$

2.19- 2.89

Type of cooking

0.003

Clean

$1.95 \%$

$1.73-2.20$

Unclean

$2.64 \%$

$2.25-3.10$

CI: confidence interval. The $P$ value was calculated using Chi-square 
492 Table 3 Relationship of risk factors and the prevalence of asthma from the 493 multivariable regression analysis

\begin{tabular}{lll}
\hline Risk factor & OR $(95 \% \mathrm{CI})$ & $P$ \\
\hline Race & 1.00 &.. \\
Han (reference) & $1.54(1.114-2.122)$ & 0.009 \\
Minorities & & \\
Age & 1.00 &.. \\
$45-49$ years (reference) & $1.80(0.830-3.893)$ & 0.137 \\
$50-59$ years & $2.65(1.230-5.702)$ & 0.013 \\
$60-69$ years & $3.74(1.741-8.036)$ & 0.001
\end{tabular}

\section{Education}

High-school or above $\quad 1.00$

(reference)

Middle-school $\quad 1.91(0.678-1.193) \quad 0.009$

Primary education $\quad 2.59(0.675-1.199)<0.001$

$\begin{array}{lll}\text { Literate } & 2.60(0.480-0.928) & <0.001\end{array}$

$\begin{array}{lll}\text { Illiterate } & 2.89(0.220-0.572) & <0.001\end{array}$

\section{Geographic region}

East (reference) $\quad 1.00$

$\begin{array}{lll}\text { North } & 1.51(1.102-2.078) & 0.010\end{array}$ 
Northeast

Northwest

South Central

Southwest China

\section{Smoking status}

Never-smokers (reference) $\quad 1.00$

Smokers

$1.36(1.109-1.677)$

0.003

\section{Type of cooking}

Clean (reference) $\quad 1.00$

Unclean

$1.07(0.859-1.323)$

0.563

494

OR: odds ratio; CI: confidence interval.

495

496

497

498

499

500

501

502

503

504 
506 Fig. 1 Geographic and population distribution of 28 provinces/cities in the CHARLS

507 in 2018. Each province/city on the map is gradually darkens in color as the number of

508 participants increases.

509 Fig. 2. Flow chart for subjects enrolled in this study. Missing data refers to

510 incompleteness of demographic/geographic/lifestyle information

511

512

513

514

515

516

517

518

519

520

521

522

523

524

525 


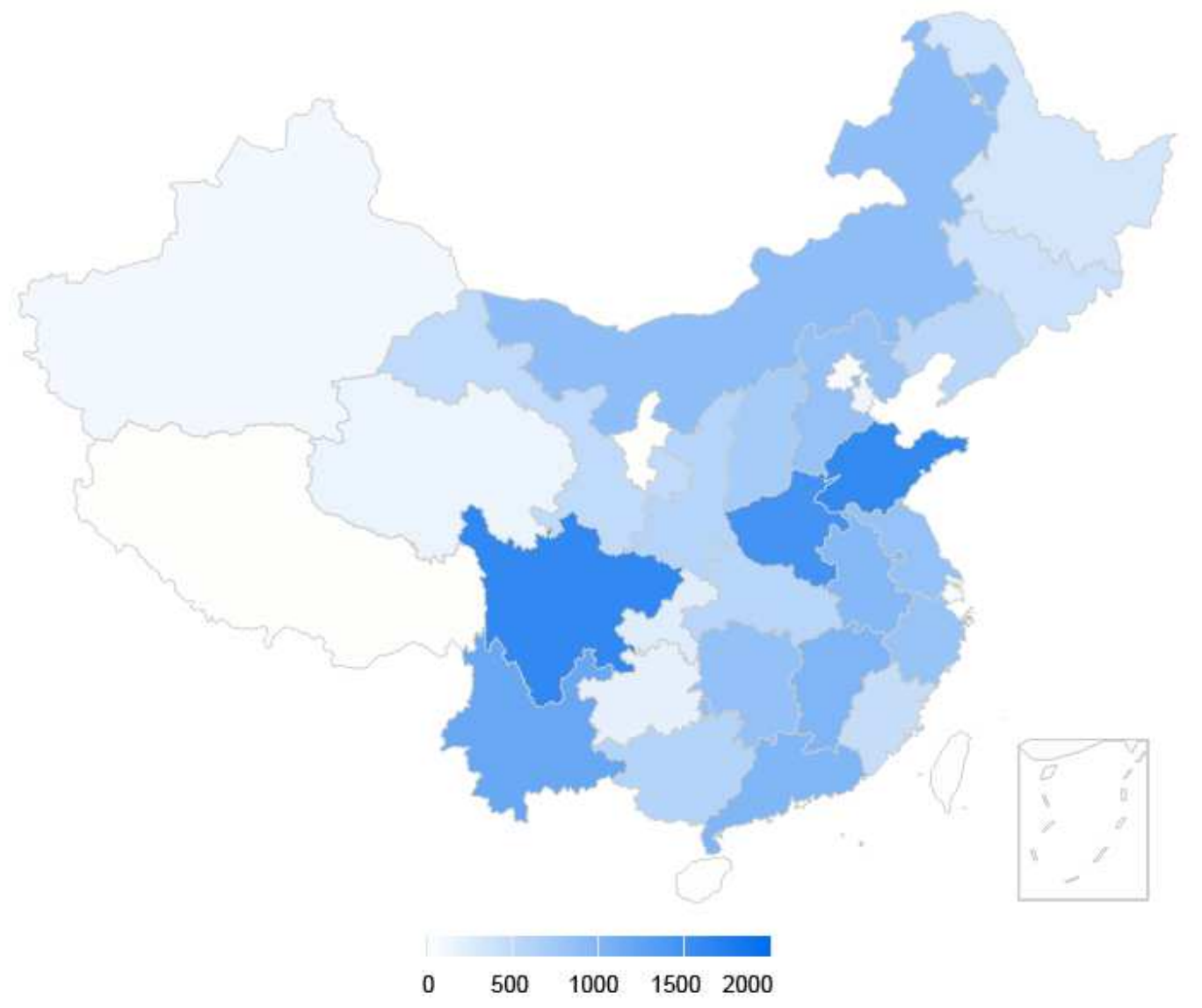

526

527

Fig. 1

528

529

530

531

532

533

534

535

536 


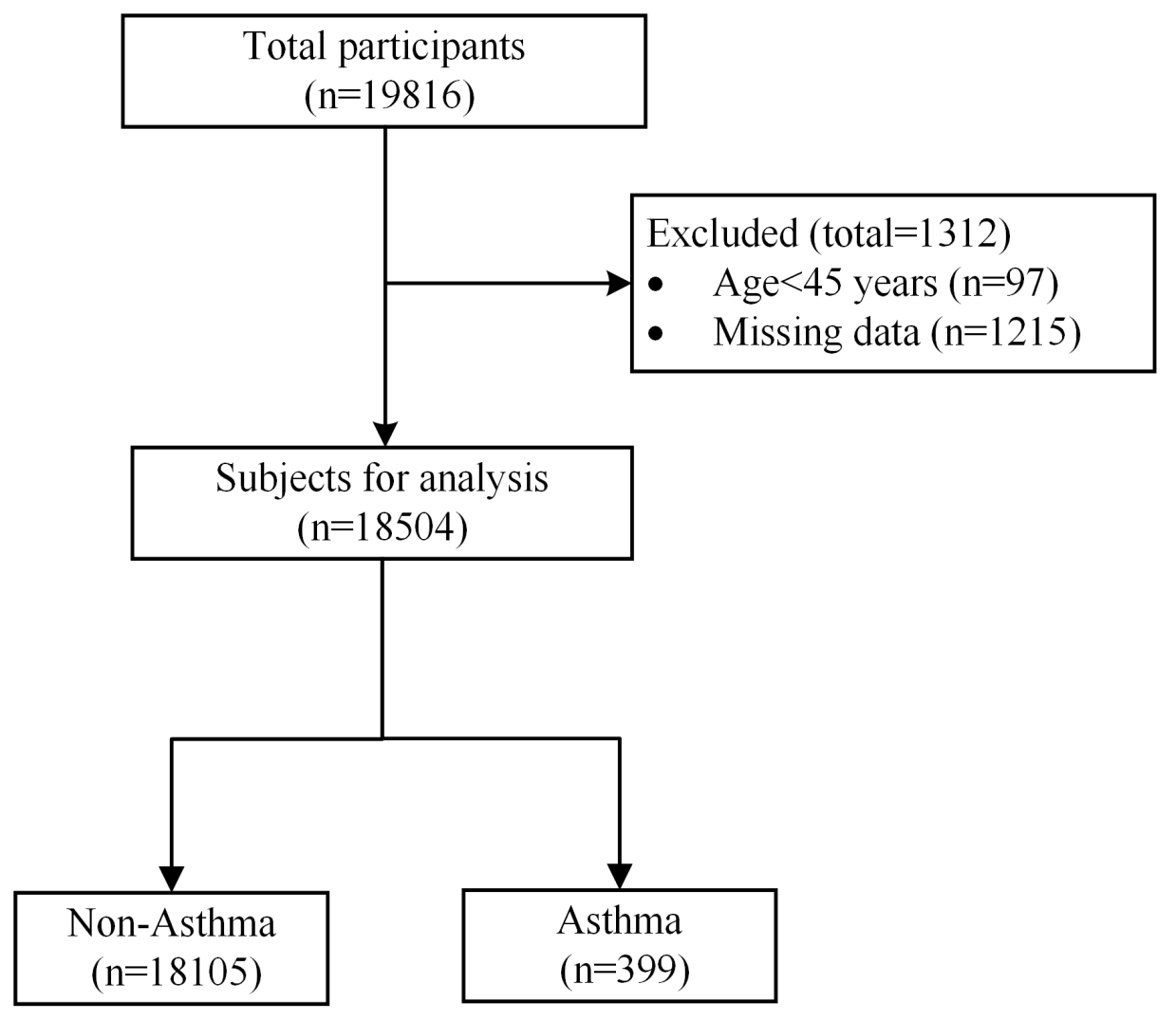

537

Fig. 2 


\section{Figures}

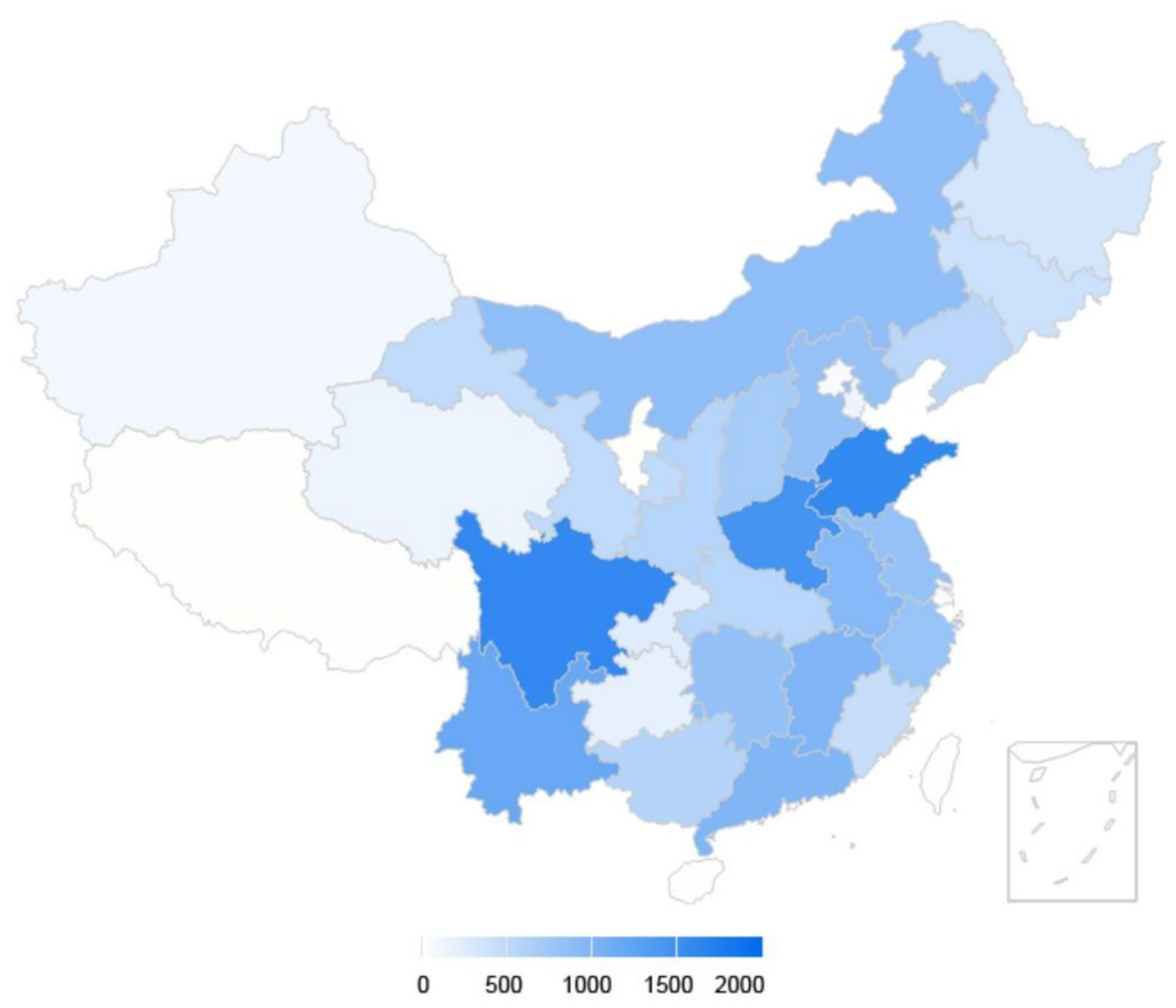

\section{Figure 1}

Geographic and population distribution of 28 provinces/cities in the CHARLS in 2018. Each province/city on the map is gradually darkens in color as the number of participants increases. Note: The designations employed and the presentation of the material on this map do not imply the expression of any opinion whatsoever on the part of Research Square concerning the legal status of any country, territory, city or area or of its authorities, or concerning the delimitation of its frontiers or boundaries. This map has been provided by the authors. 


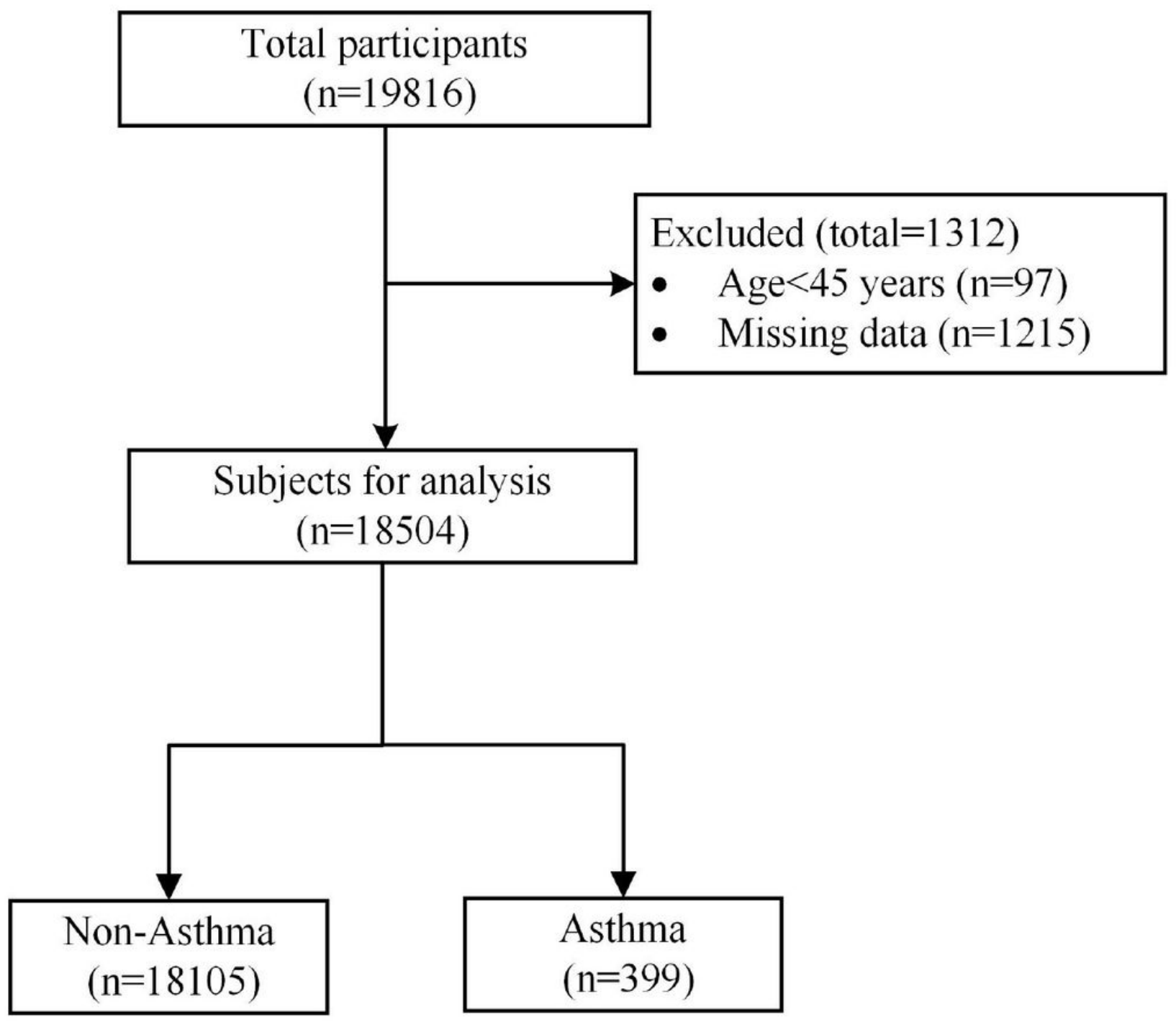

Figure 2

Flow chart for subjects enrolled in this study. Missing data refers to incompleteness of demographic/geographic/lifestyle information 